\title{
Terpenóides com atividade sobre o Sistema Nervoso Central (SNC)
}

\author{
Carolina S. Passos, Marcelo D. Arbo, Stela M. K. Rates, Gilsane L. von Poser* \\ Programa de Pós-Graduação em Ciências Farmacêuticas, Faculdade de Farmácia, Universidade Federal do Rio \\ Grande do Sul, Av. Ipiranga, 2752, 90610-000 Porto Alegre-RS, Brasil
}

\begin{abstract}
RESUMO: Os terpenóides constituem um vasto grupo de metabólitos secundários com ações sobre o SNC, destacando-se suas atividades sedativa, ansiolítica, antinociceptiva, anticonvulsivante, pró-convulsivante e alucinógena. Neste trabalho foi realizada uma revisão bibliográfica sobre terpenóides com ações descritas no SNC, enfocando moléculas e sistemas neurotransmissores relacionados com sua atividade. As substâncias abordadas encontram-se divididas em mono, sesqui, di, tri e meroterpenóides e incluem compostos isolados e plantas que apresentam ação principalmente sobre os sistemas neurotransmissores GABAérgico, glutamatérgico, dopaminérgico e opióide.
\end{abstract}

Unitermos: Terpenóides, sistema nervoso central, neurotransmissores.

\begin{abstract}
Terpenoids with activity in the Central Nervous System (CNS)". The terpenoids are a large group of secondary metabolites which display many activities in the CNS, such as sedative, ansiolytic, antinociceptive, anticonvulsant, pro-convulsant and hallucinogenic. In this work we performed a research on terpenoids that exert effects on the CNS, focusing molecules and neurotransmitter systems related to their actions. The substances approached were classified as mono, sesqui, di, tri and meroterpenoids and include isolated compounds and plants which exert activities mainly on GABAergic, glutamatergic, dopaminergic and opioid neurotransmitter systems.
\end{abstract}

Keywords: Terpenoids, central nervous system, neurotransmitters.

\section{INTRODUÇÃO}

Produtos naturais constituem uma importante fonte de pesquisa visando a descoberta de novas substâncias com atividades farmacológicas (Butler, 2004; Albuquerque \& Hanazaki, 2006). Compostos isolados de fontes vegetais também fornecem moldes estruturais para a obtenção de substâncias sintéticas e, além disso, podem ser empregados como ferramentas na identificação de mecanismos de ação (McKeena, 1996).

Plantas com atividade psicoativa exercem importantes efeitos sobre a consciência, as emoções e a cognição e, devido a esses efeitos, têm sido utilizadas há bastante tempo com finalidades terapêuticas, espirituais e recreacionais. A investigação farmacológica de produtos naturais que apresentam atividade sobre o sistema nervoso central (SNC) tem auxiliado a compreensão das bases neuroquímicas de muitas doenças. Extratos vegetais e produtos isolados exercem suas ações através de interações com moléculas endógenas transdutoras de sinal (neurotransmissores) (O'Konor \& Roth, 2005; Barbosa-Filho et al., 2006; Cardoso-Lopes et al., 2008; Quintans-Júnior et al., 2008; Sousa et al., 2008; Subhan et al., 2008).

Dentre os metabólitos secundários vegetais, os terpenóides, substâncias cuja origem biossintética deriva de unidades do isopreno, constituem o maior grupo. Na medicina popular, assim como na terapêutica, plantas contendo derivados terpênicos têm sido usadas como sedativas, tranqüilizantes e anticonvulsivantes. Muitos óleos voláteis possuem uma grande variedade de atividades farmacológicas, tais como ansiolítica, anticonvulsivante e antinociceptiva. Compostos como linalool, limoneno e citronelol possuem ação anticonvulsivante, enquanto mentol e mirceno, atividade analgésica. Muitos derivados monoterpênicos têm demonstrado atividades sobre o SNC, incluindo sedativa, antinociceptiva e antidepressiva (Pergentino de Souza et al., 2007; Sousa et al., 2007; Perazzo et al., 2007, 2008; Leite et al., 2008).

$\mathrm{O}$ presente trabalho propõe uma revisão sobre terpenos com ações descritas no SNC, enfocando principalmente os sistemas neurotransmissores relacionados a estas. A pesquisa bibliográfica incluiu um período de 10 anos (1997-2007) e foi realizada em sites de busca especializados (Pubmed, Science Direct, Web of Science, Scopus, Scirus), empregando-se diferentes combinações das seguintes palavras-chave: central nervous activity, terpenes, monoterpenes, sesquiterpenes, diterpenes, saponins e alguns terpenos 
classicamente reconhecidos por sua atividade central, tais como valepotriates, ginkolides, forskolin, linalool, ginsenosides, tujone e cannabinoids. Foram também consultadas referências citadas nos artigos encontrados na busca inicial.

\section{MONOTERPENÓIDES}

\section{Linalool}

O linalool (1) é um monoterpeno presente no óleo volátil de muitas plantas aromáticas. Muitas espécies que sintetizam essa substância são empregadas em práticas de medicina tradicional, como Aeolanthus suaveolens G. Dom (Lamiaceae) que é utilizado como anticonvulsivante na Amazônia brasileira (Re et al., 2000). Estudos farmacológicos com o linalool demonstraram que este apresenta um amplo espectro de ação em modelos experimentais de epilepsia em camundongos, destacando-se proteção contra convulsões induzidas por pentilenotetrazol, picrotoxina e eletrochoques (Silva Brum et al., 2001).

Em estudo de Elisabetsky et al. (1995) verificouse que o linalool é capaz de inibir a ligação de $\left[{ }^{3} \mathrm{H}\right]$ glutamato e de $\left[{ }^{3} \mathrm{H}\right]$ dizocilpina a membranas do córtex cerebral, o que indica a participação da transmissão glutamatérgica em seu mecanismo de ação. Em trabalho posterior (Silva Brum et al., 2001), que avaliou os efeitos do linalool sobre a liberação (basal e estimulada por $\mathrm{K}^{+}$) de $\left[{ }^{3} \mathrm{H}\right]$ glutamato e sobre a recaptação de $\left[{ }^{3} \mathrm{H}\right]$ glutamato por sinaptossomas do córtex cerebral de camundongos, foi demonstrada uma redução significativa na liberação de glutamato estimulada por $\mathrm{K}^{+}$e também na sua recaptação. Esses dois estudos sugerem a atuação do linalool no sistema glutamatérgico.

Os efeitos antinociceptivos descritos para este monoterpeno (Peana et al., 2004a) também podem estar relacionados à atividade sobre a neurotransmissão glutamatérgica, visto que o antagonismo a receptores NMDA é capaz de provocar analgesia supra-espinhal mediada pela estimulação de receptores opióides centrais e de receptores dopaminérgicos D1/D2 (Peana et al., 2004b).

\section{$\alpha$-Tujona}

$\alpha$-Tujona (2) é um monoterpeno que ocorre em muitas plantas, incluindo espécies do gênero Artemisia e Salvia. Devido aos seus efeitos alucinógenos, é o componente psicotrópico do absinto, bebida cujo uso recreacional atingiu a popularidade no século XIX e começo do século XX.

Os efeitos agudos da $\alpha$-tujona incluem, principalmente, convulsões, enquanto a ingestão crônica do absinto pode levar a alucinações, sonolência, tremores, convulsões e paralisia, uma síndrome chamada absintismo (Deilm et al., 2004). Os mecanismos que acarretam estes efeitos ainda não foram completamente elucidados, mas incluem antagonismo não-competitivo de receptores $\mathrm{GABA}_{\mathrm{A}}$, responsáveis pela ação pró-convulsivante (Höld et al., 2000), e desensibilização de receptores 5-HT (Deilm et al., 2004). Apesar da similaridade estrutural da tujona com o $\Delta^{1}$-tetraidrocanabinol $\left(\Delta^{1}\right.$-THC), a hipótese da ativação de receptores canabinóides $C B_{1}$ não foi demonstrada experimentalmente (Meschler \& Howlett, 1999).

\section{Borneol}

(+)-Borneol é um monoterpeno bicíclico presente no óleo volátil de muitas plantas medicinais, incluindo Valeriana officinalis L. (Valerianaceae), Matricaria chamomilla L. (Asteraceae) e Lavandula officinalis Chaix \& Kitt. (Lamiaceae). Extratos destas plantas são usados tradicionalmente para aliviar sintomas de ansiedade, cansaço e insônia, e também para provocar analgesia e anestesia. Estudos eletrofisiológicos in vitro mostraram que altas concentrações $(>1,5 \mathrm{mM})$ de (+)- e (-)-borneol (3) ativam diretamente receptores $\mathrm{GABA}_{\mathrm{A}}$, com fraca atividade agonista parcial. Apesar da fraca potência, a eficácia destes compostos na modulação positiva de respostas mediadas por GABA é equivalente ao anestésico etomidato e muito maior que a do diazepam e do neuroesteróide $5 \alpha$-pregnan- $3 \alpha$-ol20-ona. No entanto a modulação positiva sobre o canal não está relacionada à ligação no sítio benzodiazepínico (Granger et al., 2005).

\section{Valepotriatos}

Os valepotriatos (4) constituem o mais importante grupo químico presente em vegetais da família Valerianaceae (Valeriana officinalis L., Valeriana wallichii D.C., Valeriana edulis Nutt.) (Bos et al., 2002). Esses iridóides, substâncias instáveis quimicamente, são capazes de potencializar a anestesia induzida por hexobarbital, diminuir a agressividade, apresentar efeitos anticonvulsivantes (modelos de convulsões induzidas por pentilenotetrazol e estricnina), aumentar o tempo de sono induzido por barbitúricos, reduzir a atividade locomotora e exercer efeitos sedativos dose-dependentes (Ortiz et al., 1999). Também foi demonstrado que uma mistura de valepotriatos, bem como extratos de valeriana, foram capazes de atenuar os sintomas provocados pela síndrome de abstinência de benzodiazepínicos sem induzir efeitos tóxicos significativos. Esses resultados, juntamente com outros trabalhos, sugerem que os efeitos dos valepotriatos sobre o SNC se devem a sua atuação sobre a neurotransmissão GABAérgica (Ortiz et al., 1999; Poyares et al., 2002).

\section{Outros monoterpenóides}

Muitos componentes presentes em óleos voláteis potenciam a neurotransmissão GABAérgica, indicando a sua potencialidade para o desenvolvimento de fármacos ansiolíticos e/ou anticonvulsivantes. Estudos eletrofisiológicos in vitro com cis-jasmona, jasmim-lactona, óxido de linalool e metil-jasmonato demonstraram que todos potencializaram significativamente a corrente iônica induzida por GABA. Além disso, cis-jasmona e metil- 
jasmonato prolongaram o tempo de sono induzido por pentobarbital em camundongos (Hossain et al., 2004). Um comportamento semelhante foi observado para os isômeros da R-(-) e S-(+) da carvona, que aumentaram o tempo de latência de convulsões induzidas por pentilenotetrazol e picrotoxina, respostas mediadas por receptores $\mathrm{GABA}_{\mathrm{A}}$, indicando um efeito depressor sobre o SNC (Pergentino de Souza et al., 2007).

Por outro lado, as propriedades convulsivas de muitos óleos voláteis são conhecidas desde a segunda metade do século XIX. Os óleos voláteis próconvulsivantes contêm um ou vários monoterpenos oxigenados, a maioria são cetonas bicíclicas, todas muito similares na estrutura química e biossíntese. O mecanismo de ação deste efeito tóxico ainda é desconhecido, entretanto os óleos voláteis compartilham com o pentilenotetrazol a mesma ação inibitória sobre a respiração celular em fatias de cérebro de ratos, levando a perda do gradiente tecidual de $\mathrm{Na}^{+}$e $\mathrm{K}^{+}$e ao aumento significativo da excitabilidade celular. Entre os monoterpenos cuja toxicidade pode se manifestar através de crises convulsivas, estão cineol, fenchona, pinocanfona, pulegona, cânfora, tujona e sabinilacetato (Burkhard et al., 1999).

O extrato hidroalcoolico de Aloysia polystachya Griseb. (Verbenaceae), planta aromática nativa da América do Sul e popularmente usada no tratamento de desordens gatrintestinais e como sedativa, possui atividades ansiolítica, no labirinto em cruz elevado; e antidepressiva, no teste da natação forçada, em roedores. Estudos químicos reportaram a presença de muitos compostos monoterpênicos no óleo volátil desta planta, principalmente $\alpha$-e $\beta$-tujona e carvona, juntamente com limoneno, sabineno, $\beta$-pineno, carvacrol e eucarvona (Mora et al., 2005). Já a exposição prolongada ao óleo volátil de limão (Citrus limon L.), que possui grande quantidade de limoneno, provocou ação ansiogênica no labirinto em cruz elevado (Ceccarelli et al., 2004).

Em um screening in vitro de plantas utilizadas na medicina popular no tratamento de disfunções cognitivas, foram encontradas algumas espécies com atividade inibidora da enzima acetilcolinesterase, tais como Ruta graveolens L. (Rutaceae), Lavandula angustifolia Miller (Lamiaceae), Rosmarinus officinalis L. (Lamiaceae), Petroselium crispum (Mil.) Nym. Ex A. W. Hill. (Apiaceae), Mentha spicata L. (Lamiaceae) e Pimpinella anisum L.(Apiaceae) que contêm óleos voláteis com grande quantidade e diversidade de monoterpenos (Adsersen et al., 2006). Estudo semelhante, realizado com plantas utilizadas no Líbano, demonstrou a mesma atividade para Melissa officinalis L. (Lamiaceae), que contem citral em seu óleo volátil, e Salvia triloba L.f. (Lamiaceae). Extratos etanólicos destas mesmas plantas também apresentaram ligação a receptores GABA $_{\mathrm{A}}$ (Salah \& Jäger, 2005). A inibição da atividade da acetilcolinesterase também já foi relatada para o óleo volátil de Centella asiatica L. (Apiaceae), que contêm os monoterpenos acetato de bornil, $\alpha$-pineno, $\beta$-pineno e $\gamma$-terpineno (Howes \& Houghton, 2003).

\section{SESQUITERPENÓIDES}

\section{Ácido valerênico}

O ácido valerênico (5) é um sesquiterpeno encontrado em Valeriana officinalis e também em outras espécies de Valeriana. Essa substância é capaz de potencializar a atividade do GABA no SNC por exercer um efeito inibitório sobre a enzima ácido $\gamma$-aminobutiríco transaminase, enzima responsável pela inativação do GABA no tecido cerebral (Houghton, 1999). Assim como os valepotriatos e o borneol, o ácido valerênico também contribui para a ação depressora do SNC e para os efeitos calmantes descritos para extratos de valeriana (Ortiz et al., 1999).

Dietz et al. (2005) realizaram estudo com o objetivo de investigar os efeitos de extratos de valeriana e de ácido valerênico sobre receptores serotoninérgicos $5-\mathrm{HT}_{5 \mathrm{a}}$. Nesse trabalho foi demonstrado que duas frações do extrato bruto de valeriana, diclorometano (DCM) e éter de petróleo (EP), apresentaram alta afinidade de ligação a esse subtipo de receptor, sendo a afinidade da fração EP maior que a da fração DCM (a concentração de ácido valerênico na fração EP é mais alta que na fração DCM). Esses resultados podem contribuir para a elucidação do mecanismo do efeito sedativo exercido por valeriana, visto que a serotonina é um neurotransmissor envolvido na regulação do ciclo de sono e vigília e também do ritmo circadiano através da ação sobre receptores cerebrais acoplados a proteína $\mathrm{G}$, como $5-\mathrm{HT}_{5 \mathrm{a}}$.

\section{Artemisinina}

Artemisinina (6), lactona sesquiterpênica obtida de folhas de Artemisia annua L. (Asteraceae) e empregada no tratamento de malária cerebral provocada por cepas de Plasmodium falciparum resistentes a cloroquina, apresenta caráter hidrofóbico e tem a capacidade de atravessar membranas biológicas, incluindo a barreira hematoencefálica, facilmente. Em ensaios in vivo foi possível observar que a administração de altas doses de artemisinina causou redução nas atividades de estereotipia induzida por apomorfina e hiperatividade induzida por bromocriptina, sugerindo atividade sedativa possivelmente mediada pelo antagonismo de receptores dopaminérgicos pós-sinápticos do tipo $\mathrm{D}_{2}$. A atividade sedativa foi corroborada pela capacidade apresentada por essa substância de potencializar o tempo de sono induzido por barbitúricos (Amos et al., 2003).

\section{Outros sesquiterpenóides}


Estudos farmacológicos com sesquiterpenos isolados de Polygonum viscosum Buch-Ham. Ex D. Don (Polygonaceae) indicaram atividade analgésica do tipo opióide no teste da placa-quente. Entre os compostos, ácido viscozulênico apresentou atividade moderada, enquanto ácido viscosúmico e viscoazucina atividade fraca. Na avaliação do efeito geral sobre o SNC no teste do campo aberto, viscoazucina e viscoazulona exibiram significativa atividade depressora central, evidenciada pela diminuição da atividade locomotora. Da mesma forma, ácido viscosúmico apresentou ação depressora moderada e ácido viscozulênico ação fraca (Datta et al., 2004).

\section{DITERPENÓIDES}

\section{Gincolídeos}

O extrato padronizado de Ginkgo biloba L. (Ginkgoaceae), EGb-761, apresenta efeitos antioxidante e modulador de muitos sistemas neurotransmissores, tais como serotoninérgico, noradrenérgico, dopaminérgico e colinérgico, além de provocar aumento no fluxo sanguíneo cerebral. O gincolídeo B (7), um dos principais constituintes terpênicos desse extrato, é um potente antagonista do receptor do fator de agregação plaquetária (PAF). No SNC, a ativação do PAF estimula a geração do segundo mensageiro trifosfato de inositol $\left(\mathrm{IP}_{3}\right)$, que atua mobilizando o $\mathrm{Ca}^{2+}$ intacelular $\left(\left[\mathrm{Ca}^{2+}\right]_{\mathrm{i}}\right)$, evento associado com processos de excitotoxicidade. Receptores PAF são expressos tanto em neurônios quanto em células gliais. Em neurônios hipocampais, alguns receptores PAF estão co-localizados com receptores NMDA, responsáveis por processos como potenciação de longa duração, que atua na consolidação de memória (Maclennan et al., 2002).

Em estudo de Brochet et al. (1999), foi demonstrado que gincolídeo B e bilobalídeo (um sesquiterpeno que corresponde a aproximadamente 3\% de EGb-761) provocaram redução no tempo de sono induzido por pentobarbital sódico em camundongos e também aumentaram o tempo de latência para início do sono. No entanto, esse efeito não foi observado para gincolídeo A, outro diterpeno presente em EGb-761, e para uma fração desse extrato livre de trilactonas terpênicas (gincolídeos A e B e bilobalídeo). Esses resultados indicam o envolvimento dos contituintes terpênicos de EGb-761 na redução do tempo de sono induzido por barbitúricos e sugerem a atuação destas substâncias como estimulantes do SNC, podendo contribuir para o entendimento do mecanismo pelo qual EGb-761 auxilia na melhora da capacidade cognitiva.

\section{Forscolina}

Forscolina (8), um diterpeno isolado de Plectranthus forskohlii Willd. (Lamiaceae), apresenta propriedades anti-hipertensivas em modelos animais além de ser um potente ativador específico da enzima adenilato ciclase. Esta enzima está envolvida em eventos celulares mediados por segundos mensageiros, bastante importantes em processos envolvidos na transmissão neuronal (McKeena, 1996). Esse diterpeno é empregado experimentalmente como um ativador da adenilato ciclase, provocando aumento na geração de AMPc. Wang \& Zhuo (2002) demonstraram que coaplicação de forscolina e serotonina causou facilitação da resposta sináptica mediada por receptores NMDA em neurônios sensitivos da medula espinhal.

\section{Salvinorina A}

Salvinorina A (9) é o constituinte ativo de Salvia divinorum Epling \& Játiva (Lamiaceae), planta usada pelos índios Mazatecas de Oaxaca (México) em rituais místico-religiosos devido as suas propriedades alucinógenas. Em humanos, uma dose de 200 a 500 $\mu \mathrm{g}$ deste diterpeno produz alucinações profundas com duração de aproximadamente uma hora, potência similar a dos alucinógenos sintéticos dietilamina do ácido lisérgico (LSD) e 2,5-dimetóxi-4-bromanfetamina (DOB, cápsula do vento). S. divinorum vem sendo usada como um substituto da maconha (Sheffler \& Roth, 2003). Curiosamente, diferente de outras substâncias alucinógenas clássicas, o alvo molecular responsável por sua ação não são os receptores serotoninérgicos $5-\mathrm{HT}_{2 \mathrm{~A}}$. Estudos in vitro e in vivo indicaram que salvinorina A é um agonista pleno dos receptores opióides $\kappa$, responsável pelos efeitos analgésico e psicotomimético (Sheffler \& Roth, 2003; Yan \& Roth, 2004; Prisinzano, 2005; John et al., 2006; McCurdy et al., 2006).

\section{TRITERPENÓIDES}

\section{Ginsenosídeos}

Ginsenosídeos são saponinas triterpênicas encontradas em Panax ginseng C. A. Meyer (Araliaceae). Alguns estudos têm demonstrado que o ginseng é capaz de provocar efeitos benéficos no SNC como, por exemplo, melhora na aquisição de aprendizado e na consolidação de memória em alguns modelos experimentais e, também, diminuição da morte neuronal associada a processos isquêmicos e a toxicidade provocada por glutamato. Em estudo realizado com saponinas totais de ginseng, observou-se que estas são capazes de inibir a ação do glutamato mediada por receptores NMDA, sendo que o ginsenosídeo $\mathrm{Rg}_{3}$, um dos constituintes majoritários, apresentou maior potência para inibição de sinais mediados por NMDA (Kim et al., 2002). 
<smiles>C=C[C@](C)(O)CCC=C(C)C</smiles><smiles>C=C[C@](C)(O)CCC=C(C)C</smiles><smiles>CC(C)C12CCC(CC1=O)C2C</smiles><smiles>CC1C2CCC(C)(C1O)C2(C)C</smiles><smiles>C[C@H]1[C@H]2CC[C@@](C)([C@@H]1O)C2(C)C</smiles>

3<smiles>CC(=O)OCC1=COC(CC(=O)CC(C)C)C2C1=CC(OC(=O)CC(C)C)C21CO1</smiles>

4

Figura 1. Estrutura química de alguns monoterpenóides.<smiles>CC1=C2C(/C=C(\C)C(=O)O)CC[C@@H](C)C2CC1</smiles>

5

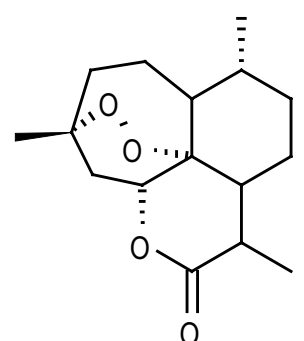

6

Figura 2. Estrutura química de alguns sesquiterpenóides.

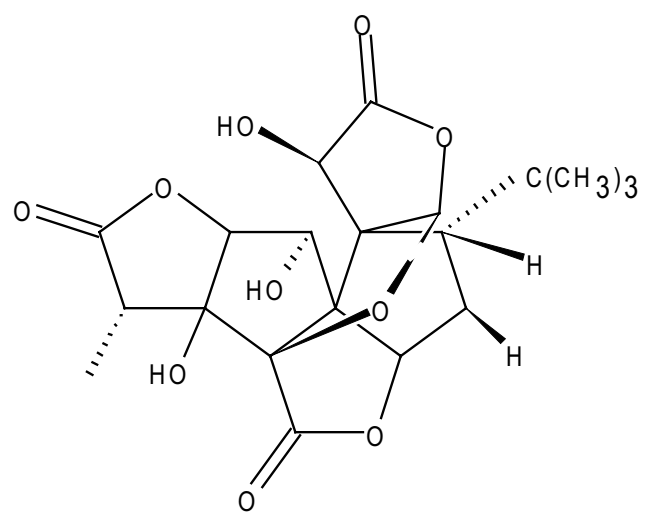

7<smiles>C=C[C@]1(C)CC(=O)[C@@]2(C)[C@@](C)(O1)[C@@H](OC(C)=O)C(O)[C@@H]1C(C)(C)CC[C@@H](O)[C@]12C</smiles>

8<smiles>C=C(OC)[C@H]1C[C@@H](OC(C)=O)C(=O)[C@H]2[C@@H]3C[C@H](c4ccoc4)OC(=O)[C@@]34CC[C@H]1[C@@H]24</smiles>

9

Figura 3. Estrutura química de alguns diterpenóides. 


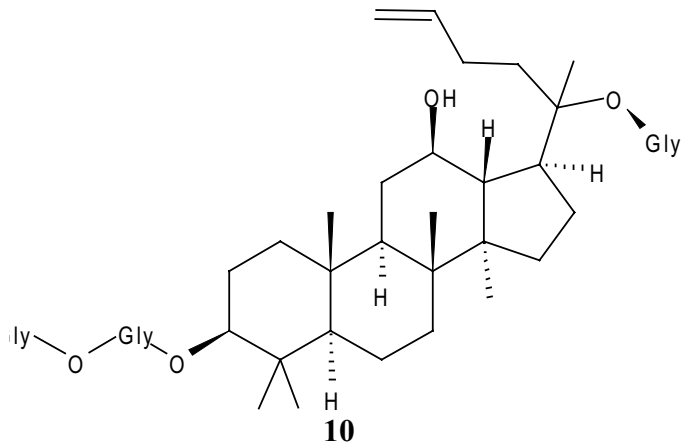

Figura 4. Estrutura química do triterpenóide ginsenosídeo $\mathrm{R}_{\mathrm{g} 1}$.

$\mathrm{Li}$ et al. (2007) avaliaram os efeitos do ginsenosídeo $\mathrm{R}_{\mathrm{g} 2}$ sobre a neurotoxicidade induzida por glutamato em células PC12. Os autores verificaram que essa saponina atenuou os efeitos neurotóxicos provocados por glutamato em todas as doses testadas $(0,05 ; 0,1$ e $0,2 \mu \mathrm{mol} / \mathrm{L})$, sugerindo uma atividade neuroprotetora mediada por inibição do influxo de $\mathrm{Ca}^{2+}$, diminuição da peroxidação lipídica e sub-regulação da expressão de fatores pró-apoptóticos. Também foi observado que o ginsenosídeo $\mathrm{R}_{\mathrm{g} 2}$ é capaz de inibir a formação do peptídeo beta-amilóide $A \beta 1-40$, podendo representar uma estratégia potencial para o tratamento da Doença de Alzheimer.

Os ginsenosídeos $R_{b 1}$ (10) e $R_{g 1}$ também apresentaram atividade neuroprotetora sobre diferentes tipos de células neuronais (Radad et al., 2006). Lim et al. (1997) demonstraram que a administração intracerebroventricular do ginsenosídeo $R_{b 1}$ protegeu neurônios hipocampais (CA1) contra o dano letal isquêmico, provavelmente através de uma atividade seqüestradora de radicais livres. Em ensaio in vitro, os ginsenosídeos $\mathrm{R}_{\mathrm{b} 1}$ e $\mathrm{R}_{\mathrm{g} 1}$ protegeram neurônios da medula espinhal contra a excitotoxicidade induzida por glutamato e ácido caínico, bem como do estresse oxidativo provocado por peróxido de hidrogênio (Liao et al., 2002).

Os ginsenosídeos também têm apresentado efeitos benéficos em alguns modelos de doenças neurodegenerativas, como Parkinson (Radad et al., 2006). Em ensaios com culturas de células dopaminérgicas foi demonstrado que os ginsenosídeos $\mathrm{R}_{\mathrm{b} 1}$ e $\mathrm{R}_{\mathrm{g} 1}$ aumentaram a sobrevivência dessas células e promoveram crescimento neurítico após exposição à $\mathrm{MPP}^{+}$ou glutamato (Radad et al., 2004a; 2004b). Os mecanismos envolvidos no efeito protetor destes compostos sobre os neurônios dopaminérgicos ainda não estão completamente elucidados. No entanto, já foi demonstrado que alguns ginsenosídeos inibem a recaptação de dopamina em sinaptossomas de ratos.

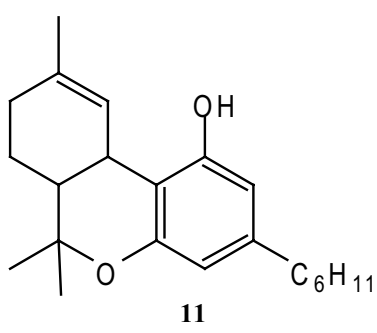

Figura 5. Estrutura química do meroterpenóide $\Delta^{1}$-tetraidrocanabinol (THC).

Também foi verificado que o ginseng provocou supressão do estresse oxidativo induzido pela autooxidadação da dopamina e que atenuou processos apoptóticos induzidos por $\mathrm{MPP}^{+}$(Radad et al., 2006).

As raízes de ginseng são tradicionalmente utilizadas para tratar doenças psiquiátricas, como ansiedade e depressão. Estudos empregando modelos animais de ansiedade indicaram que $P$. ginseng apresenta atividade ansiolítica provavelmente relacionada à presença de saponinas (Cha et al., 2004; Park et al., 2005; Carr et al., 2006). A avaliação da atividade ansiolítica dos ginsenosídeos $\mathrm{R}_{\mathrm{b} 1}, \mathrm{R}_{\mathrm{g} 1}, \mathrm{R}_{\mathrm{g} 3}-\mathrm{R}$ e $\mathrm{R}_{\mathrm{g} 3}-\mathrm{S}$, bem como de uma mistura dos ginsenosídeos $\mathrm{R}_{\mathrm{g} 5}$ e $\mathrm{R}_{\mathrm{k}}$, no modelo do labirinto em cruz elevado indicou que $\mathrm{R}_{\mathrm{b} 1}, \mathrm{R}_{\mathrm{g} 1}$ e a mistura de $\mathrm{R}_{\mathrm{g} 5}$ e $\mathrm{R}_{\mathrm{k}}$ apresentaram atividade ansiolítica caracterizada pelo aumento significativo no número de entradas e no tempo gasto nos braços abertos. Além disso, o ginsenosídeo $\mathrm{R}_{\mathrm{b} 1} \mathrm{e}$ a mistura de $\mathrm{R}_{\mathrm{g} 5}$ e $\mathrm{R}_{\mathrm{k}}$ provocaram uma diminuição da atividade locomotora similar àquela provocada pelo diazepam (Cha et al., 2005). Em trabalho posterior, Carr et al. (2006) avaliaram a atividade de extrato de $P$. ginseng, de frações saponínicas e não-saponínicas do extrato e dos ginsenosídeos $\mathrm{R}_{\mathrm{b} 1}, \mathrm{R}_{\mathrm{g} 1}$ e $\mathrm{R}_{\mathrm{o}}$ no mesmo modelo comportamental. Os pesquisadores observaram atividade ansiolítica para o extrato de ginseng (1200 $\mathrm{ng} / \mathrm{kg}$ ), para a fração saponínica do extrato (100 mg/ $\mathrm{kg}$ ) e para o ginsenosídeo $\mathrm{R}_{\mathrm{b} 1}(5 \mathrm{e} 10 \mathrm{mg} / \mathrm{kg})$. Ainda nesse estudo, foi demonstrado que $\mathrm{R}_{\mathrm{b} 1}$ não provocou alterações significativas na atividade locomotora.

O mecanismo envolvido na atividade ansiolítica dos ginsenosídeos ainda não está completamente elucidado. No entanto, é provável que o complexo receptor $\mathrm{GABA}_{\mathrm{A}}$-benzodiazepínico esteja relacionado a essa atividade. Além disso, os efeitos sedativos atribuídos à administração de doses elevadas de ginseng, junto com a atividade ansiolítica causada pelo emprego de doses menores, apóiam a hipótese do envolvimento do sistema GABAérgico no mecanismo de ação dos 
ginsenosídeos (Park et al., 2005).

\section{Outros triterpenóides}

Estudo com plantas utilizadas na Coréia para aprimorar as funções cognitivas, verificou ação inibidora da acetilcolinesterase para Dioscorea batatas Deene (Dioscoreaceae), que apresenta, entre outros constituintes, a saponina esteroidal dioscina, e Bupleurum falcatum L. (Apiaceae), que tem entre seus metabólitos secundários uma série de saponinas triterpênicas (saicosídeos) com efeitos sedativos e analgésicos (Oh et al., 2004).

O extrato alcoólico de Centella asiatica (L.) Urban. (Apiaceae) mostrou ter um efeito tranqüilizante quando administrado em ratos, atividade atribuída ao triterpeno bramosídeo. Já o ácido asiático, triterpeno obtido também de C. asiatica, protegeu neurônios corticais da excitotoxicidade glutamatérgica in vitro, demonstrando o potencial terapêutico dessa planta no tratamento de enfermidades do SNC (Howes \& Houghton, 2003).

Poligalasaponinas, de Polygala tenuifolia Willd. (Polygalaceae), possuem propriedades antagonistas de receptores dopaminérgicos e serotoninérgicos, sendo esta planta indicada na Medicina Tradicional Chinesa para o tratamento de psicoses. O extrato aquoso de $P$. tenuifolia prolongou o tempo de sono induzido por hexabarbital, efeito atribuído à presença de onjisaponina $\mathrm{F}$, sugerindo atividade GABAérgica para este componente (Howes \& Houghton, 2003).

O extrato hidroalcoólico das partes subterrâneas de Pfaffia glomerata Spreng. (Amaranthaceae), comercializada no Brasil como uma substituta do ginseng (Panax spp.), apresentou atividade depressora do SNC no teste de convulsões induzidas por pentilenotetrazol e efeito amnésico no teste da esquiva inibitória. Os principais constituintes deste extrato são saponinas nortriterpênicas derivadas do ácido pfáfico (De Paris et al., 2000).

\section{MEROTERPENÓIDES}

\section{Canabinóides}

Cannabis sativa L. (Cannabaceae) vem sendo utilizada, há séculos, pela humanidade para diversos fins, tais como, alimentação, rituais religiosos e práticas medicinais, onde apresenta grande potencial terapêutico, apesar de suas propriedades psicotrópicas. O seu uso medicinal é permitido hoje em alguns estados norteamericanos e países como Holanda, Bélgica e Canadá, para aliviar sintomas relacionados ao tratamento de câncer, AIDS, esclerose múltipla e síndrome de Tourette. A atividade biológica da planta se deve a uma série de compostos com 21 átomos de carbono, os canabinóides, estruturas terpenofenólicas que não foram isoladas de qualquer outra espécie vegetal ou animal. Dentre os canabinóides, o mais importante, devido ao seu efeito psicotrópico, é o $\Delta^{1}$-tetraidrocanabinol $\left(\Delta^{1}\right.$ THC) (11). No SNC, algumas atividades terapêuticas relatadas são analgésica, controle de espasmos em pacientes portadores de esclerose múltipla, ansiolítica e anticonvulsivante, mas podem ser acompanhadas de efeitos adversos como alterações na cognição e memória, euforia, depressão e sedação (Honório et al., 2006).

No final da década de 80 , foi descoberto que o THC se liga especificamente a receptores canabinóides acoplados à proteína $\mathrm{G}$ no encéfalo, principalmente nas áreas do controle motor, no córtex cerebral e nas vias da dor. Dois tipos de receptores canabinóides são conhecidos atualmente: receptores $\mathrm{CB} 1$, localizados no encéfalo, e receptores $\mathrm{CB} 2$, que se localizam no sistema periférico sendo expressos principalmente por células imunes (Bear et al., 2002; Honório et al., 2006). Os receptores CB1 e CB2 junto com os ligantes canabinóides endógenos (anandamida, 2-AG, noladin éter, virodamina e NADA) constituem o sistema endocanabinóide. Os endocanabinóides são derivados do ácido araquidônico, o que os diferencia estruturalmente dos fitocanabinóides (Grotenhermen, 2005).

Leweke et al. (2004) relataram que os receptores canabinóides e seus ligantes endógenos estão alterados em pacientes esquizofrênicos. Estudos com WIN 55,212-2, um agonista sintético de receptores canabinóides, indicaram que a ativação de receptores CB1 pode estar associada com o desenvolvimento de psicoses (Arguello \& Jentsch, 2004). O canabidiol, um fitocanabinóide que atua como antagonista de receptores CB1, vem sedo estudado como uma possível substância antipsicótica. Estudo de Zuardi et al. (1991) indicou que o canabidiol reduziu de forma significativa os efeitos psicóticos causados pelo $\Delta^{1}$-THC em animais e humanos. O perfil farmacológico apresentado por essa substância mostrou-se semelhante ao de antipsicóticos atípicos (Moreira \& Guimarães, 2005). As propriedades antipsicóticas do canabidiol também foram investigadas em estudos clínicos nos quais se verificou que o tratamento com esse fitocanabinóide atenuava os efeitos psicóticos (Bosi et al., 2003; Leweke et al., 2006).

\section{CONSIDERAÇÕES FINAIS}

O uso de plantas contendo terpenos na medicina popular é bem conhecido; estudos científicos sobre a atividade dos terpenóides sobre o SNC são mais recentes. Estes estudos incluem, além da avaliação em modelos de doenças neuropsiquiátricas, também a busca dos seus alvos moleculares de ação. As atividades avaliadas in vivo estão relacionadas aos propósitos de uso popular como sedativo e ansiolítico. Os alvos moleculares estudados são, principalmente, os sistemas neurotransmissores GABAérgico, glutamatérgico, 
dopaminérgico e opióide. De uma forma geral, o conjunto dos dados demonstra o potencial terapêutico, e em alguns casos tóxico, dessa classe de metabólitos secundários, sugerindo a necessidade de estudos de relação estrutura-atividade, visando à modulação de suas propriedades biológicas e possibilitando a obtenção de protótipos farmacológicos mais eficazes e seguros.

\section{REFERÊNCIAS}

Adsersen A, Gauguin B, Gudiksen L, Jäger AK 2006. Screening of plants used in Danish folk medicine to treat memory dysfunction for acetylcholinesterase inhibitory activity. J Ethnopharmacol 104: 418-422.

Albuquerque UP, Hanazaki N 2006. As pesquisas etnodirigidas na descoberta de novos fármacos de interesse médico e farmacêutico: fragilidades e pespectivas. Rev Bras Farmacogn 16(Supl.): 678-689.

Amos S, Vhindo BA, Abbah J, Vongtau HO Edmond I, Binda L, Akah PA, Wambebe C, Gamaniel KS 2003. Postsynaptic dopamine $\left(\mathrm{D}_{2}\right)$-mediated behavioural effects of high acute doses of artemisinin in rodents. Brain Res Bull 62: 255-260.

Arguello PA, Jentsch JD 2004. Cannabinoid CB1 receptormediated impairment of visuospatial attention in the rat. Psychopharmacology 177: 141-50.

Barbosa-Filho JM, Medeiros KCP, Diniz MFFM, Batista LM, Athayde-Filho PF, Silva MS, Cunha EVL, Almeida JRGS, Quintans-Júnior LJ 2006. Natural products inhibitors of the enzyme acetylcholinesterase. Rev Bras Farmacogn 16: 258-285.

Bear MF, Connors BW, Paradiso MA 2002. Neurociências: desvendando o sistema nervoso. Porto Alegre: Artmed.

Bos R, Woerdenbag, HJ, Pras N 2002.Determination of valepotriates. J Chromatogr A 967: 131-146.

Bosi DC, Hallak JEC, Dursun SM, Deakin JFW, Zuardi AW 2003. Effects of cannabidiol on (s)-ketamineinduced psychopathology in healthy volunteers. $J$ Psychopharmacol 17 (Suppl): A55.

Brochet D, Chermat R, DeFeudis FV, Drieu K 1999. Effects of single intraperitoneal injections of an extract of Ginkgo biloba (EGb 761) and its terpene trilactone constituents on barbital-induced narcosis in the mouse. Gen Pharmacol 33: 249-256.

Burkhard PR, Burkhardt K, Haenggeli C-A, Landis T 1999. Plant-induced seizures: reappearance of an old problem. J Neurol 246: 667-670.

Butler MS 2004. The role of natural product chemistry in drug discovery. J Nat Prod 67: 2141-2153.

Cardoso-Lopes EM, Carreira RC, Agripino DG, Torres LMB, Cordeiro I, Bolzani VS, Dietrich SMC, Young MCM 2008. Screening for antifungal, DNA-damaging and anticholinesterasic activities of Brazilian plants from the Atlantic Rainforest - Ilha do Cardoso State Park. Rev Bras Farmacogn 18 (Supl.): 655-660.

Carr MN, Bekku N, Yoshimura H 2006. Identification of anxiolytic ingredients in ginseng root using the elevated plus-maze test in mice. Eur J Pharmacol 531: 160-165.

Cha HY, Seo JJ, Park JH, Choi KJ, Hong JT, Oh KW 2004. Anxiolytic effects of total saponin fraction from
Ginseng radix rubra on the elevated plus-maze model in mice. $J$ Ginseng Res 28: 132-135.

Cha HY, Park JH, Hong JT, Yoo HS, Song S, Hwang BY, Eun JS, Oh KH 2005. Anxiolytic-like effects of ginsenosides on the elevated plus maze model in mice. Biol Pharm Bull 28: 1621-1625.

Ceccarelli I, Lariviere WR, Fiorenzani P, Sacerdote P, Aloisi AM 2004. Effects of long-term exposure of lemon essential oil odor on behavioral, hormonal and neuronal parameters in male and female rats. Brain Res 1001: 78-86.

Datta BK, Datta SK, Chowdhury MM, Khan Th, Kundu JK, Rashid MA, Nahar L, Sarker SD 2004. Analgesic, antiinflamatory and CNS depressant activities of sesquiterpenes and a flavonoid glycoside from Polygonum viscosum. Pharmazie 59: 222-225.

De Paris F. Neves G, Salgueiro JB, Quevedo J, Izquierdo I, Rates SMK 2000. Psycopharmacological screening of Pfaffia glomerata Spreng. (Amaranthaceae) in rodents. J Ethnopharmacol 73: 261-269.

Deiml T, Haseneder R, Zieglgänsberger W, Rammes G, Eisensamer B, Rupprecht R, Hapfelmeier G 2004. $\alpha$-Thujone reduces $5-\mathrm{HT}_{3}$ receptor activity by an effect on the agonist-induced desensitization. Neuropharmacol 46: 192-201.

Dietz BM, Mahady GB, Pauli GF, Farnsworth NR 2005. Valerian extract and valerenic acid are partial agonists of the 5-HT5a receptor in vitro. Mol Brain Res 138: 191-197.

Elisabetsky E, Silva Brum, LF, Souza DO 1995. Anticonvulsant properties of linalool on glutamate related seizure. Phytomedicine 6: 113-119.

Granger RE, Campbell EL, Johnston GAR 2005. (+)- And (-)-borneol: efficacious positive modulators of GABA action at human recombinant $\alpha_{1} \beta_{2} \gamma_{2 L}$ GABA $_{\mathrm{A}}$ receptors. Biochem Pharmacol 69: 1101-1111.

Grotenhermen F 2005 Cannabinoids. Curr Drug Targets CNS Neurol Disord 4: 507-530.

Höld KM, Sirisoma NS, Ikeda T, Narahashi T, Casida JE 2000. $\alpha$-Thujone (the active component of absinthe): $\gamma$-aminobutiric acid type A receptor modulation and metabolic detoxification. Proc Natl Acad Sci USA 97: 3826-3831.

Honório KM, Arroio A, Ferreira da Silva AB 2006. Aspectos terapêuticos de compostos da planta Cannabis sativa. Quim Nova 29: 318-325.

Hossain SJ, Aoshima H, Koda H, Kiso Y 2004. Fragrances in Oolong tea that enhance the response of $\mathrm{GABA}_{\mathrm{A}}$ receptors. Biosci Biotechnol Biochem 68: 1842-1848.

Houghton PJ 1999. The scientific basis for the reputated avtivity of valerian. J Pharm Pharmacol 51: 505512.

Howes M-JR, Houghton PJ 2003. Plants used in Chinese and Indian tradicional medicine for improvement of memory and cognitive function. Pharmacol Biochem Behav 75: 513-527.

John TF, French LG, Erlichman JS 2006. The antinociceptive effect of salvinorin A in mice. Eur J Pharmacol 545: 129-133.

Kim S, Anh K, Oh TH, Nah SY, Rhim H 2002. Inhibitory effect of ginsenosides on NMDA receptor-mediated signals in rat hippocampal neurons. Biochem Biophys Res Commun 296: 247-254. 
Leite MP, Fassin Jr. J, Baziloni EMF, Almeida RN, Mattei R, Leite JR 2008. Behavioral effects of essential oil of Citrus aurantium L. inhalation in rats. Rev Bras Farmacogn 18 (Supl.): 661-666.

Leweke FM, Gerth CW, Klosterkotter J 2004. Cannabisassociated psychosis: current status of research. CNS Drugs 18: 895-910.

Leweke FM, Koethe D, Gerth CW 2006. Cannabidiol as an antipsychotic: a double-blind, controlled clinical trial on cannabidiol vs amisulpride in acute schizophrenics. 2005 Symposium on the Cannabinoids, Burlington, Vermont, International Cannabinoid Research Society apud: Zuardi AW, Crippa JA, Hallak JE, Moreira FA, Guimaraes FS. Cannabidiol, a Cannabis sativa constituent, as an antipsychotic drug. Braz J Med Biol Res 39: 421-429.

Li N, Liu B, Dluzen DE, Jin Y 2007. Protective effects of ginsenoside $\mathrm{R}_{\mathrm{g} 2}$ against glutamate-induced neurotoxicity in PC12 cells. J Ethnopharmacol 111: 458-463.

Liao B, Newmark H, Zhou R 2002. Neuroprotective effects of ginseng total saponin and ginsenosides $\mathrm{Rb} 1$ and $\mathrm{Rg} 1$ on spinal cord neurons in vitro. Exp Neurol 173: 224-234.

Lim JH, Wen TC, Matsuda S, Tanaka J, Maeda N, Peng H, Aburaya J, Ishihara K, Sakanaka M 1997. Protection of ischemic hippocampal neurons by ginsenoside Rb1, a main ingredient of ginseng root. Neurosci Res 28: 191-200.

Maclennan KM, Darlington CL, Smith PF 2002. The CNS effects of Ginkgo biloba extracts and ginkgolide B. Prog Neurobiol 67: 235-257.

McCurdy CR, Sufka KJ, Smith GH, Warnick JE, Nieto MJ 2006. Antinociceptive profile of salvinorin A, a structurally unique kappa opioid receptor agonist. Pharmacol Biochem Behav 83: 109-113.

McKeena D 1996. Plant hallucinogens: springboards for psychotherapeutic drug discovery. Behav Brain Res 73: 109-115.

Meschler JP, Howlett AC 1999. Thujone exhibits low affinity for cannabinoid receptors but fails to evoke cannabimimetic responses. Pharmacol Biochem Behav 62: 473-480.

Mora S, Díaz-Véliz G, Millán R, Lungenstrass H, Quirós S, Coto-Morales T, Hellión-Ibarrola MC 2005. Anxiolytic and antidepressant-like effects of the hydroalcoholic extract from Aloysia polystachya in rats. Pharmacol Biochem Behav 82: 373-378.

Moreira FA, Guimaraes FS 2005. Cannabidiol inhibits the hyperlocomotion induced by psychotomimetic drugs in mice. Eur J Pharmacol 512: 199-205.

O'Connor, KA, Roth BL 2005. Screening the receptorome for plant-base psychoactive compounds. Life Sci 78 : 506-511.

Oh MH, Houghton PJ, Whang WK, Cho JH 2004. Screening of Korean herbal medicines used to improve cognitive function for anti-cholinesterase activity. Phytomed 11: 544-548.

Ortiz JG, Nieves-Natal J, Chavez P 1999. Effects of Valeriana officinalis extracts on $\left[{ }^{3} \mathrm{H}\right]$ flunitrazepam binding, synaptossomal $\left[{ }^{3} \mathrm{H}\right] \mathrm{GABA}$ uptake, and hippocampal $\left[{ }^{3} \mathrm{H}\right]$ GABA release. Neurochem Res 24: 1373-1378.

Park JH, Cha HY, Seo JJ, Hong JT, Han K, Oh KW 2005.
Anxiolytic-like effects on ginseng in the elevated plus-maze model: comparison of red ginseng and sun ginseng. Prog Neuropsychopharmacol Biol Psychiatry 29: 895-900.

Peana AT, De Montis MG, Nieddu E, Spano MT, D’Aquila PS, Pippia P 2004a. Profile of spinal and supra-spinal antinociception of (-)-linalool. Eur J Pharmacol 485: 165-174.

Peana AT, De Montis MG, Sechi S, Sircana G, D’Aquila PS, Pippia P 2004b. Effects of (-)-linalool in the acute hyperalgesia induced by carrageenan, L-glutamate and prostaglandin $\mathrm{E}_{2}$. Eur J Pharmacol 497: 279284.

Perazzo FF, Carvalho JCT, Rodrigues M, Morais EKL, Maciel MAM 2007. Comparative anti-infammatory and antinociceptive effects of terpenoids and an aqueous extract obtained from Croton cajucara Benth. Rev Bras Farmacogn 17: 521-528.

Perazzo FF, Lima LM, Maistro EL, Carvalho JE, Rehder VLG, Carvalho JCT 2008. Effect of Artemisia annua L. leaves essential oil and ethanol extract on behavioral assays. Rev Bras Farmacogn 18: 686-689.

Pergentino de Souza D, Farias Nóbrega FF, Almeida RN 2007. Influence of the chirality of $(R)-(-)-$ and $(S)-(+)-$ carvone in the central nervous system: a comparative tudy. Chirality 19: 264-268.

Poyares DR, Guilleminault C, Ohayon M, Tufik S 2002. Can valerian improve the sleep insomniacs after benzodiazepine withdrawal. Prog Neuropsychopharmacol Biol Psychiatry 26: 539545.

Prisinzano TE 2005. Psychopharmacology of the hallucinogenic sage Salvia divinorum. Life Sci 78: 527-531.

Quintans-Júnior LJ, Almeida JRGS, Lima JT, Nunes XP, Siqueira JS, Oliveira LEG, Almeida RN, AthaydeFilho PF, Barbosa-Filho JM 2008. Plants with anticonvulsant properties - a review. Rev Bras Farmacogn 18 (Supl.): 798-819.

Radad K, Gille G, Moldzio R, Saito H, Rausch WD 2004a. Ginsenosides Rb1 and Rg1 effects on mesencephalic dopaminergic cells stressed with glutamate. Brain Res 17: 41-53.

Radad K, Gille G, Moldzio R, Saito H, Ishige K, Rausch WD 2004b. Ginsenosides Rb1 and Rg1 effects on survival and neurite growth of $\mathrm{MPP}^{+}$-affected mesencephalic dopaminergic cells. J Neural Transm 111: 37-45.

Radad K, Gille G, Liu L, Rausch WD 2006. Use of ginseng in medicine with emphasis in neurodegenerative disorders. J Pharmacol Sci 100: 175-186.

Re L, Barocci S, Sonnino S, Mencarelli A, Vivani C, Paolucci G, Scarpantonio A, Mosca E 2000. Linalool modifies the nicotinic receptor-ion channel kinetics at the mouse neuromuscular junction. Pharmacol Res 42: 177-181.

Salah SM, Jäger AK 2005. Screening of traditionally used Libanese herbs for neurological activities. $J$ Ethnopharmacol 97: 145-149.

Sheffler DJ, Roth BL 2003. Salvinorin A: the 'magic mint' hallucinogen finds a molecular target in the kappa opioid receptor. Trends Pharmacol Sci 24: 107-109.

Silva Brum LF, Emanuelli T, Souza DO, Elisabetsky E 2001. Effects of linalool glutamate release and uptake in 
mouse cortical synaptossomes. Neurochem Res 26: 191-194.

Sousa DP, Nóbrega FFF, Claudino FS, Almeida RN, Leite JR, Mattei R 2007. Pharmacological effects of the monoterpene $\alpha, \beta$-epoxy-carvone in mice. Rev Bras Farmacogn 17: 170-175.

Sousa FCF, Melo CTV, Citó MCO, Félix FHC, Vasconcelos SMM, Fonteles MMF, Barbosa-Filho JM, Viana GSB 2008. Plantas medicinais e seus constituintes bioativos: Uma revisão da bioatividade e potenciais benefícios nos distúrbios da ansiedade em modelos animais. Rev Bras Farmacogn 18: 642-654.

Subhan N, Alam MA, Ahmed F, Shahid IJ, Nahar L, Sarker SD 2008. Bioactivity of Excoecaria agallocha. Rev Bras Farmacogn 18: 521-526.

Wang GD, Zhuo M 2002. Synergistic enhancement of glutamate-mediated responses by serotonin and forskolin in adult mouse spinal dorsal horn neurons. J Neurophysiol 87: 732-739.

Yan F, Roth BL 2004. Salvinorin A: a novel and highly selective $\kappa$-opioid receptor agonist. Life Sci 75: 2615-2619.

Zuardi AW, Rodrigues JA, Cunha JM 1991. Effects of cannabidiol in animal models predictive of antipsychotic activity. Psychopharmacology 104: 260-264. 